\title{
Access to liposomal generic formulations: beyond AmBisome and Doxil/Caelyx
}

\author{
Sara Gaspani; Barbara Milani
}

\section{The lack of clear regulatory guidance remains a key bottleneck for securing a second quality-assured source of liposomal amphotericin B (LAmB), the WHO-recommended drug for visceral leishmaniasis. The approval of the first generic liposomal product by the US Food and Drug Administration in February 2013 could be a turning point, and serve as a basis for WHO to develop guidance for the evaluation of generic liposomal formulations.}

Keywords: Drug access, generics, liposomal amphotericin B, liposomal doxorubicin, visceral leishmaniasis

\begin{abstract}
Discussion
Liposomal amphotericin B injectable (LAmB) is the reference drug for treatment of presumptive fungal infections in patients with febrile neutropenia, systemic fungal infections refractory to conventional amphotericin B, or visceral leishmaniasis (VL) [1-3]. Visceral leishmaniasis is a parasitic neglected disease which is fatal if left untreated. Although LAmB is included in the World Health Organization (WHO) Essential Medicines List $[4,5]$, it is difficult to access in many countries.
\end{abstract}

Global access to LAmB depends heavily upon the access policy determined by Gilead, the company that produces the innovator drug (AmBisome). There is only one single manufacturing site for the production of AmBisome, a situation that poses both challenges (in terms of output capacity) and risks (in case this site had to stop production) [6]. Gilead has been involved in multiple but still limited efforts to expand access to AmBisome for VL, including a preferential pricing policy (US\$18/vial) and a donation of 450,000 vials over five years. These initiatives are a far cry from meeting the needs of the 200,000 to 400,000 new VL patients every year. In the short term, further reductions of the 'access price' should be negotiated with Gilead, while in the longer term both demand and supply of LAmB need to be expanded. Large public procurement schemes for $\mathrm{LAmB}$ as a VL treatment could also represent an attractive market to manufacturers, who currently target only niche markets for the treatment and prophylaxis of fungal infections in countries that, or patients who can afford to pay. Implementing these initiatives will require a concerted plan to expand the pool of quality-assured LAmB suppliers for $\mathrm{VL}$, and the involvement of WHO, governments of endemic countries, and donors.

A survey carried out by Médecins Sans Frontières (MSF) in 2012 found a significant number of generic LAmB formulations already marketed or under development in low and middle-income countries. Some of these manufacturers are aiming to register their product in stringently regulated markets such as Europe and the US. Indeed, lucrative markets for LAmB will be open to Gilead's competitors within the next two to five years. AmBisome remains protected by two patents (US5874104, US5965156) in the US until 2016 and by one patent (CA1339008) in Canada until 2014.

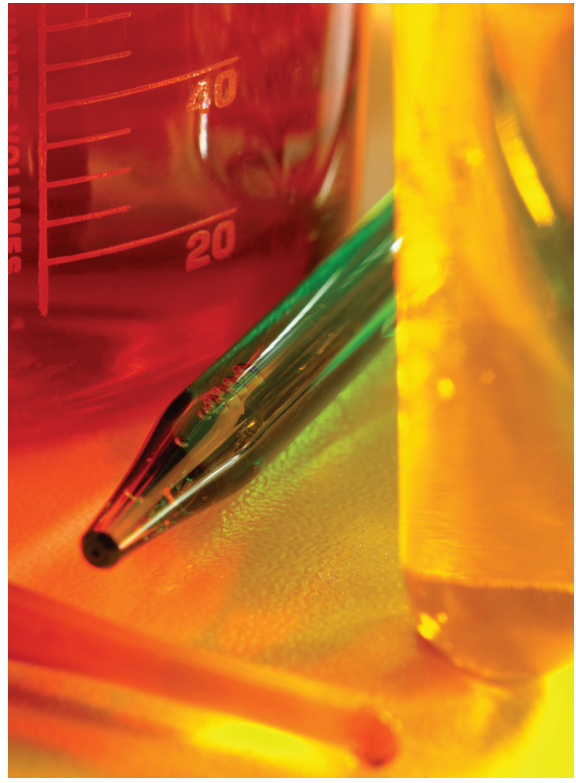

However, Gilead's monopoly on the LAmB market is likely to continue beyond these dates because producers of generic liposomal formulations are confronted not only with manufacturing and patent hurdles [7] but also with a lack of clear, transparent regulatory guidance. Stringent regulatory authorities (SRAs) have been unable to provide manufacturers wishing to enter the market with guidance on how to evaluate generic LAmB formulations, and WHO has not set any internationally recognized standards for evaluating these medicines. Nor do national drug regulatory authorities (NDRAs) of countries with a high VL burden (Bangladesh, Brazil, Ethiopia, India, Nepal, North Sudan, South Sudan), in which a generic drug competitor for LAmB could have a substantial market for VL, have specific regulatory guidance on liposomal product registration or bioequivalence assessment methods. This near-vacuum is a major obstacle to ensuring that quality-assured alternatives to the single source of AmBisome are accessible, and it could potentially lead to the marketing of products that may not present quality, efficacy and safety profiles similar to the innovator product.

Over the last decade, US and European regulatory agencies began to address the subject of liposomes by publishing draft guidance containing non-binding 
recommendations; the US Food and Drug Administration (FDA) published the first draft 'Guidance for industry on liposome drug products' in August 2002 [8]. However, this document did not provide information on bioequivalence assessment methods, and to date it is still under revision. In February 2010, FDA published a productspecific guidance to abbreviate new drug applications for pegylated liposomal doxorubicin (PLD) injectable formulations [9]. Like the earlier guidelines, this productspecific guidance is a draft containing 'nonbinding recommendations'; nevertheless, it is the only attempt in stringently regulated markets to state clearly how to prove bioequivalence. Indeed, it defines detailed standards for the evaluation of generic PLD with the same product composition and equivalent liposome characteristics, and manufactured using the same drug loading process, as the reference product. For demonstrating bioequivalence this guidance recommends using human pharmacokinetic (PK) studies and in vitro dissolutions studies.

The European Medicines Agency (EMA) published its first draft reflection paper in July 2011 [10], released as a final version in February 2013 [11]. This document aims to assist applicants in generating relevant clinical and non-clinical data to support their application for marketing authorization of intravenous liposomal products developed with reference to an innovator product. However, it does not define a specific analytical, non-clinical or clinical strategy and provides only general principles for assessing liposomal products [12]. Using this approach, the extent and complexity of non-clinical and clinical studies would be defined on a case-by-case basis.

These current EMA and FDA regulatory frameworks do not adequately support the entry of generic liposomal drugs, as they remain vague and overly general (with the notable exception of FDA productspecific guidelines on PLD). This situation could lead to a non-transparent caseby-case approach. In a context already characterized by lack of clear standards within stringently regulated markets, there are striking examples of conflicts of interest whereby innovator companies sponsor studies aimed at demonstrating how to prove bioequivalence with reference to their liposomal formulation [13, 14].

Scientific experts are questioning how to

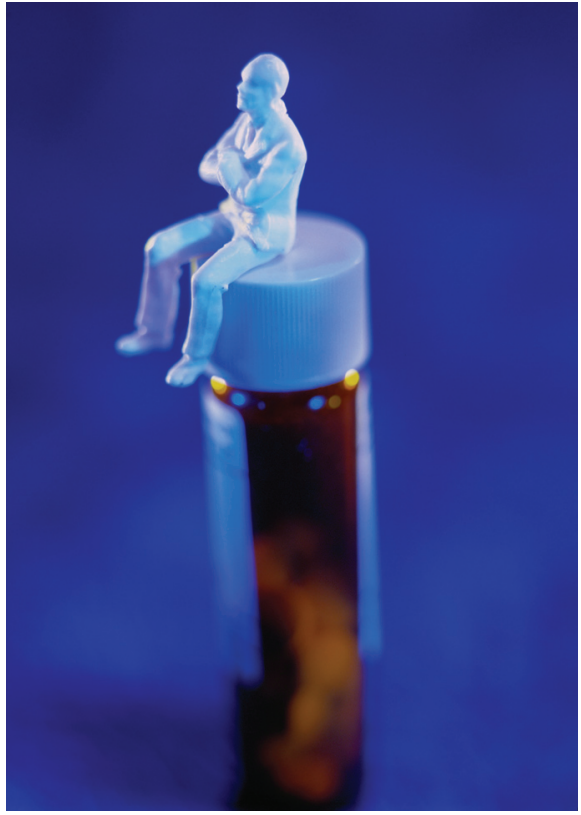

The sameness approach has been adopted in FDA product-specific guidelines for PLD in February 2013, which led to the first regulatory approval in a stringently regulated market of a generic liposomal formulation (Lipodox, Sun Pharma, India) [17]. The generics producer relied on clinical data generated for the originator product (Doxil/ Caelyx, Johnson \& Johnson) to register its product under Section 505(j) of the federal Food, Drug and Cosmetic Act classically used for generic drugs [18]. FDA initially authorized Lipodox for temporary importation and distribution in February 2012, following a worldwide shortage of the innovator version due to manufacturing problems in the single production site [19, 20].

It should be noted that Lipodox was filed for registration with EMA, but was not approved due to 'outstanding major nonclinical and clinical objections' [21], despite the fact that the EMA guidelines are unclear about standards and requirements, as discussed above. Nevertheless, since the shortage of Doxil/Caelyx began, Sun Pharma's product has been imported and used in some European countries, including Austria, Finland, Germany (Personal communication), Poland (Personal communication), Slovenia [22] and Spain [23].

According to Schellekens et al. [16], liposomal drugs can be fully characterized, based on extensive collective experience accumulated within industry and academia over the last 30 years. The main factors determining safety and efficacy are the rate and extent of drug release from the liposomal particles upon administration to the patient. Therefore, comparability to the reference product should be approached at the level of equivalence of composition and physico chemical characteristics of the generic drug product to the innovator one. If properly adapted, the classical generics approach could be applicable, with two alternative pathways depending on whether the generic drug product has been developed to mirror exactly the innovator product (sameness) or not (similar but not the same). A detailed pharmaceutical characterization supplemented with clinical PK (total drug, liposome-associated drug, free drug) would be sufficient if the sameness approach is followed. If the sameness approach cannot be followed, then preclinical animal experiments (PK, tissue distribution and efficacy) are also needed.
Lipodox's approval could be considered a precedent for removing barriers to registration of generic liposomal formulations in stringently regulated markets and for framing the international guidance on liposomal formulations geared to developing countries. The classical bioequivalence approach could also be used for LAmB, with adaptation as for pegylated liposomal doxorubicin. FDA appears to be in the process of developing product-specific guidance on LAmB (Personal communication).

\section{Conclusion}

Availability, accessibility and affordability of quality-assured LAmB depend on a series of factors. Uncertainty of the regulatory pathway is one element that, when added to technical difficulties in manufacturing and in demonstrating bioequivalence, contributes to blocking entry of generics competitors into stringently regulated markets [24]. On the other hand, it is important to ensure that generics versions marketed in poorly regulated countries present quality, efficacy and safety profiles, which ensure that patients benefit from the efficacy and low toxicity of LAmB, as opposed to conventional amphotericin $\mathrm{B}$ and other lipidic formulations. 
Securing quality-assured alternative products to AmBisome and potentially expanding the pool of LAmB suppliers will require some major steps. WHO should develop and provide guidance to countries for assessing the bioequivalence of liposomal formulations, including product-specific guidance on LAmB. Governments of endemic countries should commit to registering and using products that meet such WHO standards. And donors should support market-shaping interventions for securing at least one alternative source of LAmB for treatment of VL.

In addition to developing standards, WHO could also consider undertaking an assessment of generics alternatives using the model of the WHO pre-qualification system, while NDRAs are adopting and implementing WHO standards on the evaluation of generic liposomal formulations.

\section{Competing interests: None.}

Provenance and peer review: Not commissioned; internally peer reviewed.

\section{Co-author}

Sara Gaspani, Project Pharmacist, Médecins Sans Frontières, Access Campaign

Authors are responsible for English language editing of this manuscript.

\section{References}

1. US Food and Drug Administration. Center for drug evaluation and research. Application number: 050740. Approval letter [homepage on the Internet]. 1997 [cited 2013 May 2]. Available from: http://www.accessdata.fda.gov/drugsatfda_ docs/nda/97/050740a_081797-1.pdf

2. Balasegaram M, Ritmeijer K, Lima MA, Burza S, Ortiz Genovese G, Milani B, et al. Liposomal amphotericin $\mathrm{B}$ as a treatment for human leishmaniasis. Expert Opin Emerg Drugs. 2012 Dec;17(4):493-510. doi:10. 1517/14728214.2012.748036. Epub 2012 Nov 20.

3. World Health Organization. Control of the leishmaniases: report of a meeting of the WHO expert committee on the control of leishmaniases. Geneva: 2010 March 22-26 [homepage on the Internet]. [cited 2013 May 2]. Available from: http:// apps.who.int/iris/bitstream/10665/44412/1/ WHO_TRS_949_eng.pdf

4. World Health Organization. WHO model list of essential medicines. 17th list [homepage on the Internet]. 2011 [cited 2013 May 2]. Available from: http://whqlibdoc.who.int/hq/2011/a95053_eng.pdf

5. World Health Organization. WHO model list of essential medicines for children. 3rd list [homepage on the Internet]. 2011 [cited 2013 May 2]. Available from: http://whqlibdoc.who. int/hq/2011/a95054_eng.pdf

6. Gilead. Annual Report 2011; 2012 Feb [cited 2013 April 19]. Available from: http://investors. gilead.com $/$ phoenix $\cdot$ zhtml? $\mathrm{c}=69964 \& \mathrm{p}=$ irolreportsannual

7. Webb MS, Rebstein P, Lamson W, Bally MB. Liposomal drug delivery: recent patents and emerging opportunities. Recent Pat Drug Deliv Formul. 2007;1(3):185-94.

8. US Food and Drug Administration. Draft guidance for industry liposome drug products [homepage on the Internet]. 2002 [cited 2013 May 2]. Available from: http://www.fda.gov/downloads/Drugs/Guidance ComplianceRegulatoryInformation/Guidances/ ucm070570.pdf

9. US Food and Drug Administration. Draft guidance on doxorubicin hydrochloride [homepage on the Internet]. 2010 [cited 2013 May 2]. Available from: http://www.fda.gov/downloads/Drugs/GuidanceComplianceRegulatoryInformation/Guidances/UCM199635.pdf

10. European Medicines Agency. Draft reflection paper on the data requirements for intravenous liposomal products developed with reference to an innovator liposomal product [homepage on the Internet]. 2011 July 21 [cited 2013 May 2]. Available from: http://www.ema.europa.eu/docs/ en_GB/document_library/Scientific_guideline/2011/07/WC500109479.pdf

11. European Medicines Agency. Reflection paper on the data requirements for intravenous liposomal products developed with reference to an innovator liposomal product [homepage on the Internet]. $2013 \mathrm{Feb}$ 21 [cited 2013 May 2]. Available from: http://www. ema.europa.eu/docs/en_GB/document_library/Scientific_guideline/2013/03/WC500140351.pdf

12. European Medicines Agency. Procedure for European Union guidelines and related documents within the pharmaceutical legislative framework [homepage on the Internet]. 2009 March 18 [cited 2013 May 2]. Available from: http://www.emea. europa.eu/docs/en_GB/document_library/Scientific_guideline/2009/10/WC500004011.pdf

13. Olson JA, Adler-Moore JP, Jensen GM, Schwartz J, Dignani MC, Proffitt RT. Comparison of the physicochemical, antifungal, and toxic properties of two liposomal amphotericin B products. Antimicrob Agents Chemother. 2008 Jan;52(1): 259-68. doi:10.1128/AAC.00870-07

14. Mamidi RNVS, Weng S, Stellar S, Wang C, Yu N, Huang $T$, et al. Pharmacokinetics, efficacy and toxicity of different pegylated liposomal doxorubicin formulations in preclinical models: is a conventional bioequivalence approach sufficient to ensure therapeutic equivalence of pegylated liposomal doxorubicin products? Cancer Chemother Pharmacol. 2010;66(6):1173-84.

15. European Medicines Agency. 1st International Workshop on Nanomedicines 2010 Summary
Report, EMA/538503/2010 [homepage on the Internet]. 2010 Oct 21 [cited 2013 May 2]. Available from: http://www.ema.europa.eu/docs/en_GB/document_library/Report/2010/10/WC500098380.pdf

16. Schellekens H, Klinger E, Mühlebach S, Brin JF, Storm G. The therapeutic equivalence of complex drugs. Regul Toxicol Pharmacol. 2011;59(1):176-83.

17. US Food and Drug Administration. FDA approval of generic version of cancer drug Doxil is expected to help resolve shortage [homepage on the Internet]. 2013 Feb 4 [cited 2013 May 2]. Available from: http://www.fda.gov/NewsEvents/ Newsroom/PressAnnouncements/ucm337872.htm

18. US Food and Drug Administration. FDA CDER to Ortho-Biotech Products, L.P. - Petition partial approval and denial [homepage on the Internet]. 2013 [cited 2013 May 2]. Available from: http:// www.regulations.gov/\#!documentDetail;D=FDA2009-P-0216-0005

19. US Food and Drug Administration. Doxorubicin hydrochloride liposome injection [homepage on the Internet]. 2012 Feb 21 [cited 2013 May 2]. Available from: http://www.fda.gov/Drugs/InformationOnDrugs/ApprovedDrugs/ucm292721.htm

20. US Food and Drug Administration. Frequently asked questions: temporary importation of Lipodox Doxorubicin HCL liposomal injection [homepage on the Internet]. 2012 [cited 2013 May 2]. Available from: http://www.fda.gov/ downloads/Drugs/DrugSafety/DrugShortages/ UCM295225.pdf

21. European Medicines Agency. CHMP assessment report: Doxorubicin SUN [homepage on the Internet]. 2011 [cited 2013 May 2]. Available from: http://www.ema.europa.eu/docs/en_GB/ document_library/Application_withdrawal_assessment_report/human/002049/WC500112957.pdf

22. Slovenian Ministry of Health Medicines Central Database, Authorisation to import Lipodox $2 \mathrm{mg} / \mathrm{ml}$ inj [homepage on the Internet]. 2012 [cited 2013 May 2]. Available from: http://www. cbz.si/cbz/bazazdr2.nsf/Search?SearchView\&Qu ery $=(\% 5$ BTXIMELAS1\%5D=_lipodox* $) \&$ SearchOr der $=4 \&$ SearchMax $=301$

23. Agencia Española de Medicamentos y Productos Sanitarios. Importación temporal de Lipodox $2 \mathrm{mg} / \mathrm{ml}$, concentrado para perfusión intravenosa (doxorubicina HCL liposomal) [homepage on the Internet] 2012 July 13 [cited 2013 May 2]. Spanish. Available from: http://www.aemps. gob.es/informa/notasInformativas/medicamentosUsoHumano/problemasSuministro/2012/ NI-MUH_11-2012.htm. Available from: http:// www.aemps.gob.es/informa/notasInformativas/ medicamentosUsoHumano/problemasSuministro/2012/docs/NI-MUH_11-2012.pdf

24. Burgess P. On firm ground: IP protection of therapeutic nanoparticles. Nat Biotechnol. 2010 Dec;28(12):1267-70.

DOI: 10.5639/gabij.2013.0202.022

Copyright (c) 2013 Pro Pharma Communications International 